\title{
Article
}

\section{Theoretical Studies of Acrolein Hydrogenation to Propenol and Propanal on $\mathrm{Au}_{3}$ and $\mathrm{Au} 5$}

\author{
Guo-Jun Kang ${ }^{1}$, Shuai $\mathrm{He}^{1}$ and Xue-Feng Ren ${ }^{1,2, *}$ \\ 1 Low Carbon Energy Institute, School of Chemical Engineering \& Technology, \\ China University of Mining \& Technology, Xuzhou 221008, China; \\ gjkang@cumt.edu.cn (G.-J.K.); kingfeng030611@163.com (S.H.) \\ 2 Fukui Institute for Fundamental Chemistry, Kyoto University, 34-4 Takano Nishihiraki-cho, Sakyo, \\ Kyoto 606-8103, Japan \\ * Correspondence: renx@@cumt.edu.cn
}

\begin{abstract}
The stepwise hydrogenation of the $\mathrm{C}=\mathrm{C}$ bond and $\mathrm{C}=\mathrm{O}$ group of acrolein on $\mathrm{Au} 3$ and $\mathrm{Au} 5$ model systems is investigated using the density functional theory(DFT) PW91 functional. Our results show that the $\mathrm{C}=\mathrm{C}$ hydrogenation is more favorable than that of $\mathrm{C}=\mathrm{O}$ bond on $\mathrm{Au}$ s with the barriers of the rate-determining step being 0.35 and $0.62 \mathrm{eV}$ respectively. On the other hand, the $\mathrm{C}=\mathrm{O}$ reduction is preferred over the hydrogenation of the $\mathrm{C}=\mathrm{C}$ bond on Aus. The corresponding barriers of the rate-determining steps are 0.45 and $0.54 \mathrm{eV}$, respectively. This demonstrated that the second hydrogenation step controls the reaction on both $\mathrm{Au}_{3}$ and $\mathrm{Au}_{5}$ for $\mathrm{C}=\mathrm{O}$ and $\mathrm{C}=\mathrm{C}$ hydrogenation and the $\mathrm{C}=\mathrm{O}$ hydrogenation on $\mathrm{Au} 5$ is preferred over the hydrogenation of the $\mathrm{C}=\mathrm{C}$ bond, which is helpful to address the reactivity of small size-selected supported gold clusters.
\end{abstract}

Keywords: acrolein; Au Cluster; DFT

\section{Introduction}

Unsaturated alcohols which are a kind of important chemical intermediates used to synthesize pharmaceuticals and flavoring material[1,2] are usually produced via selective hydrogenation of $\alpha$, $\beta$-unsaturated aldehydes. Normally the $C=C$ bond is more active than the $C=O$ bond both thermodynamically and kinetically[3]. Acrolein is the smallest $\alpha, \beta$-unsaturated aldehyde molecule containing conjugated $\mathrm{C}=\mathrm{C}$ and $\mathrm{C}=\mathrm{O}$ double bond, and is used as a probe molecule to study the hydrogenation activity toward the $\mathrm{C}=\mathrm{C}$ and $\mathrm{C}=\mathrm{O}$ bonds on the $\mathrm{Ag}[4-7], \mathrm{Pt}[8-11], \mathrm{Ni} / \mathrm{Pt}(111)[12,13]$ surface both experimentally and theoretically. However, the selective hydrogenation of acrolein to propenol is considered the most difficult one and the selectivity to unsaturated alcohols on conventional catalysts of group VIII metals is generally low ( $2 \%$ on Pt)[9]. It is a challenging task to increase the selectivity for the unsaturated alcohols with respect to the saturated aldehydes.

Recently gold exhibits unexpected activity for the selective hydrogenation of $\alpha, \beta$-unsaturated aldehydes to unsaturated alcohols.[14-17] Experimental studies substantiated the crucial role of $\mathrm{Au}$ as an active component in the selective hydrogenation. But the periodic density functional calculation of our group showed that acrolein is very weakly adsorbed on the clean regular $\mathrm{Au}(111)$ or the flat $\mathrm{Au}(110)$ surface[18]. A higher selectivity had been obtained on supported gold nano-particles[9]. Gold supported on $\mathrm{TiO}_{2}, \mathrm{Al}_{2} \mathrm{O}_{3}$ or $\mathrm{SiO}_{2}$ was demonstrated to catalyze alkene hydrogenation, and it was suggested that small gold clusters were the catalytically active species.[14, 15]

Although there are already many studies in the literature about the selective hydrogenation of acrolein on the different metal surfaces and supported metal catalysts, little information is known 
about acrolein hydrogenation on the gold clusters. No doubt, a comprehensive knowledge of hydrogenation of acrolein on the gold cluster is very instructive for improving the performance of the known noble metal catalysts and for screening new and better candidates. In this paper, we address acrolein hydrogenation on Au clusters. The whole paper is arranged as follows. The favorable pathways of $\mathrm{C}=\mathrm{C}$ and $\mathrm{C}=\mathrm{O}$ hydrogenation on $\mathrm{Au}_{3}$ and $\mathrm{Au} 5$ are discussed in detail in Part II. Computational methods are presented in Part III. Finally, the conclusions are presented in Part IV.

\section{Results and discussion}

\subsection{Acrolein hydrogenation on $A u 3$}

\subsubsection{Hydrogenation of the $\mathrm{C}=\mathrm{C}$ bond}

Acrolein hydrogenation is believed to follow the Houriti-Polanyi mechanism[19]. We have investigated adsorption and dissociation of $\mathrm{H}_{2}$ molecule on gold clusters and found that $\mathrm{H} 2$ dissociation can take place on $\mathrm{Au}_{3}$ and $\mathrm{Au}_{5},[20]$ and acrolein binds to $\mathrm{Au}_{3}$ and $\mathrm{Au}_{5}$ via the most strongly in di- $\sigma-(\mathrm{C}, \mathrm{O})$ mode with the binding energy of $1.52 \mathrm{eV}$ and $1.43 \mathrm{eV}$ respectively[21]. Thus, we investigated acrolein hydrogenation on gold clusters using Au3 and Au5 as representative models. Theoretically there are various hydrogenation products on the gold clusters. Now we use $\mathrm{klmn}$ to denote these species. Here $\mathrm{k}, \mathrm{l}, \mathrm{m}$ and $\mathrm{n}$ are integers which represent the number of $\mathrm{H}$ atom bonding to $\mathrm{C} 1, \mathrm{C} 2, \mathrm{C} 3$ and $\mathrm{O}$ atoms of acrolein, respectively. The atom numbering of acrolein is $\mathrm{C} 1-\mathrm{C} 2-\mathrm{C} 3-\mathrm{O} 4$ (scheme1). For example, acrolein (2110) means that there are two,one and one $\mathrm{H}$ atoms bonded to $\mathrm{C} 1, \mathrm{C} 2$ and $\mathrm{C} 3$ atoms, respectively, and the $\mathrm{O}$ atom has no $\mathrm{H}$ atom[22]. We confined our study to stepwise hydrogenation that produce the desired product propenol (2121) and the main undesired side product propanal (3210) through route 43 (R43) and route 12 (R12) (Route nm means that the first $\mathrm{H}$ atom attacks at the nth atom and the second $\mathrm{H}$ at $\mathrm{mth}$ atom. For the ordering of atoms, please see Scheme 1), respectively. In principle, there are other pathways to propenol such as R34(R21). However, according to the well-accepted mechanism and our located co-adsorption structures, these routes are excluded because the co-adsorbed $\mathrm{H}$ atoms sit quite far away from the attacked atom ( $\mathrm{C} 3$ or $\mathrm{C} 2$ respectively). It should be pointed out there are various initial states with different stability as shown in Figure A1-A4 in supporting information. However, only those from the most stable initial states are investigated here.

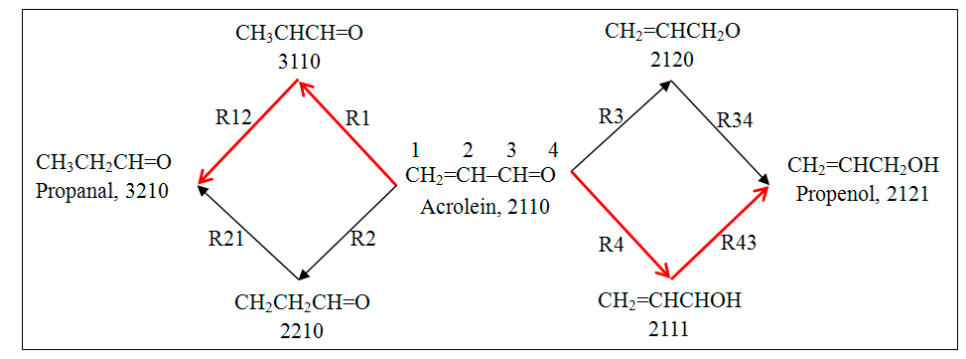

Scheme 1. Reaction pathway of acrolein hydrogenation forming the propanal and propenol. The optimal mechanism is marked in red on the Aus and Aus.

Figure 1 shows the most stable precursor structure for the hydrogenation of the $\mathrm{C}=\mathrm{C}$ bond in which the attacking $\mathrm{H}$ atom and the attacked $\mathrm{C} 1$ atom are sitting at the same gold atom (Figure 1, 3IS1) with $\mathrm{H}$-Au bond length of $1.61 \AA$. Compared to di- $\sigma-(\mathrm{C}, \mathrm{O}) / \mathrm{Au}_{3}[21]$, the $\mathrm{C} 1-\mathrm{Au}$ bond length of 3IS 1 is elongated from $2.17 \AA$ to $2.34 \AA$ and $\mathrm{C} 1-\mathrm{C} 2$ bond is stretched by $0.03 \AA$. The $\mathrm{O}-\mathrm{Au}, \mathrm{C}_{3}-\mathrm{O}$ and 
C2-C3 bond lengths vary within $0.01 \AA$. In this precursor structure, the $\mathrm{H}$ atom can only attack C1 atom. Therefore the hydrogenation route of $\mathrm{C}=\mathrm{C}$ bond follows route 12 . Attacking of the $\mathrm{H}$ atom to $\mathrm{C} 1$ leads to the $3 \mathrm{TS}_{1}$ transition state structure. In the $3 \mathrm{TS}_{1}$, the $\mathrm{H}$ atom is basically located between $\mathrm{C} 1$ and the $\mathrm{Au}$, which results in a elongated C1-Au bond distance of $3.00 \AA$, compared to $2.34 \AA$ in $3 \mathrm{IS}_{1}$. Correspondingly the $\mathrm{C} 1-\mathrm{H}$ bond reduces from $2.83 \AA$ in $3 \mathrm{IS}_{1}$ to $1.80 \AA$ in $3 \mathrm{TS}_{1}$. Generally speaking, the framework bonds change little in $3 \mathrm{TS}_{1}$ with respect to the corresponding values in $3 \mathrm{IS}_{1}$ (Figure 1). After the $3 \mathrm{TS}_{1}$, the reaction results in an intermediate product 3IM1A. In this structure, the framework changes a lot. For example, the C1-C2 bond is extended to $1.51 \AA$ while the $\mathrm{C} 2-\mathrm{C} 3$ bond is shortened by $0.05 \AA$, compared with 3TS1. The H-C1 bond is formed with the bond length of $1.11 \AA$. The produced intermediate adsorbs on $\mathrm{Au}_{3}$ mainly through $\mathrm{O}$ interaction with the substrate by the $\mathrm{O}-\mathrm{Au}$ bond reduced from $2.13 \AA$ to $2.04 \AA$.

Table 1. Energy barriers and reaction energies of the first and second step of acrolein hydrogenation on Aus and Aus. The energy of each initial state (IS) is taken as zero energy reference.

\begin{tabular}{|c|c|c|c|c|c|c|c|c|c|}
\hline \multirow{3}{*}{$\begin{array}{c}\text { step } \\
1^{\text {st }}\end{array}$} & \multicolumn{2}{|c|}{$\mathrm{Au}_{3} \mathrm{E}(\mathrm{eV})$} & \multicolumn{2}{|c|}{$\mathrm{Au}_{5} \mathrm{E}(\mathrm{eV})$} & \multirow{3}{*}{$\begin{array}{r}\text { step } \\
1^{\text {st }}\end{array}$} & \multicolumn{2}{|c|}{$\mathrm{Au}_{3} \mathrm{E}(\mathrm{eV})$} & \multicolumn{2}{|c|}{$\mathrm{Au}_{5} \mathrm{E}(\mathrm{eV})$} \\
\hline & \multicolumn{4}{|c|}{$\mathrm{C}=\mathrm{C}$} & & \multicolumn{4}{|c|}{$\mathrm{C}=\mathrm{O}$} \\
\hline & $3 \mathrm{IS}_{1}$ & 0 & $5 \mathrm{IS}_{1}$ & 0 & & $\mathrm{IS}_{4}$ & 0.00 & $5 \mathrm{IS}_{1}$ & 0 \\
\hline & $3 \mathrm{TS}_{1}$ & 0.29 & $5 \mathrm{TS}_{1}$ & 0.30 & \multirow{6}{*}{$2^{\text {nd }}$} & $3 \mathrm{TS}_{4}$ & 0.94 & $5 \mathrm{TS}_{4}$ & 0.17 \\
\hline \multirow{5}{*}{$2^{\text {nd }}$} & $3 \mathrm{IM}_{1 \mathrm{~A}}$ & 0.04 & $5 \mathrm{IM}_{1 \mathrm{~A}}$ & -0.34 & & $3 \mathrm{IM}_{4 \mathrm{~A}}$ & 0.48 & $5 \mathrm{IM}_{4 \mathrm{~A}}$ & -0.27 \\
\hline & 3IM1в & -0.38 & $5 \mathrm{IM}_{1 \mathrm{~B}}$ & -1.10 & & $3 \mathrm{IM}_{4 \mathrm{~B}}$ & 0.16 & $5 \mathrm{IM}_{4 \mathrm{~B}}$ & -0.66 \\
\hline & $3 \mathrm{IS}_{12}$ & 0 & $5 \mathrm{IS}_{12}$ & 0 & & $3 \mathrm{IS}_{43}$ & 0 & $5 \mathrm{IS}_{43}$ & 0 \\
\hline & $3 \mathrm{TS}_{12}$ & 0.35 & $5 \mathrm{TS}_{12}$ & 0.54 & & $3 \mathrm{TS}_{43}$ & 0.62 & $5 \mathrm{TS}_{43}$ & 0.45 \\
\hline & $3 F_{12}$ & 0.02 & $5 \mathrm{FS}_{12}$ & -0.62 & & $3 \mathrm{FS}_{43}$ & -0.38 & $5 \mathrm{FS}_{43}$ & -0.25 \\
\hline
\end{tabular}

A lot of calculations demonstrate species with unpaired electrons interact with the substrates favorably through the atom with its unpaired electron. However, 3IM $\mathrm{M}_{1 \mathrm{~A}}$ is not the most stable adsorption complex and it adsorbs through $\mathrm{C} 1$ and $\mathrm{O} 4$, not $\mathrm{C} 2$ which has an unpaired electron. We found that $3 \mathrm{IM}_{1 \mathrm{~B}}$ is the most stable adsorption configuration. Conversion $3 \mathrm{IM}_{1 \mathrm{~A}}$ to the most stable complex of 3ІМ 1 в releases the heat of $0.34 \mathrm{eV}$ (Table 1). In 3ІМ $\mathrm{M}_{1 в}$, the $\mathrm{H}-\mathrm{Au}$ bond is broken and the $\mathrm{C} 2-\mathrm{Au}$ bond is formed with a bond distance of $2.23 \AA$ which is shorter by $0.11 \AA$ A than C1-Au in 3IS1. Because of stronger interaction of $\mathrm{C} 2$ and $\mathrm{Au}, \mathrm{C} 2-\mathrm{C} 3$ bond is weakened and increases from $1.39 \AA$ to 
$1.46 \AA$. Simultaneously, the O-Au bond and Au-Au bond increase $0.11 \AA$ and $0.10 \AA$, respectively.

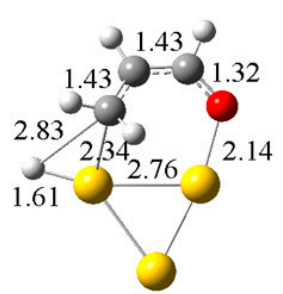

$3 \mathrm{IS}_{1}$

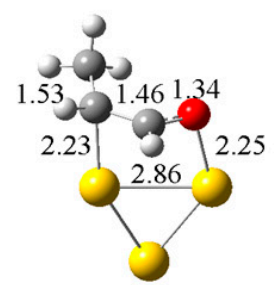

3IM 1 в

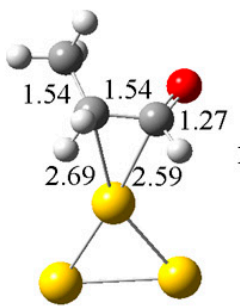

$3 \mathrm{FS}_{12}$

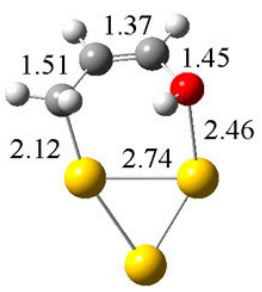

$3 \mathrm{IM}_{4 \mathrm{~A}}$

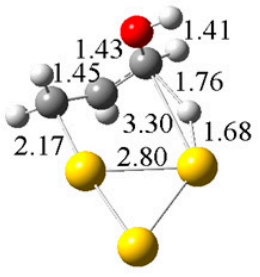

$3 \mathrm{TS}_{43}$

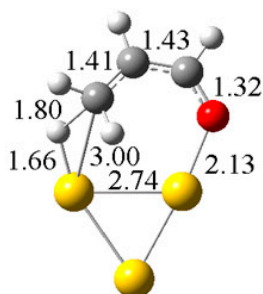

$3 \mathrm{TS}_{1}$

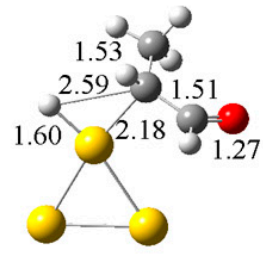

$3 \mathrm{IS}_{12}$

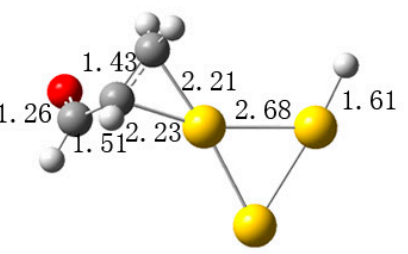

$3 \mathrm{IS}_{4}$

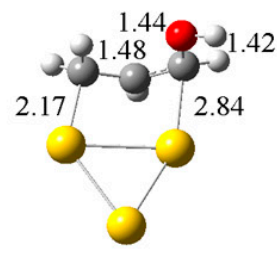

$3 \mathrm{IM}_{4 \mathrm{~B}}$

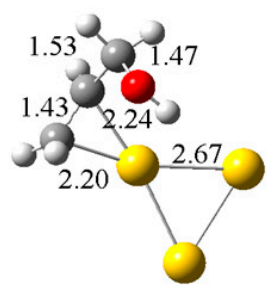

$3 \mathrm{FS}_{43}$

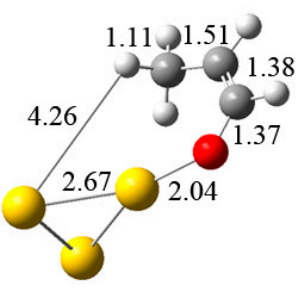

$3 \mathrm{IM}_{1 \mathrm{~A}}$

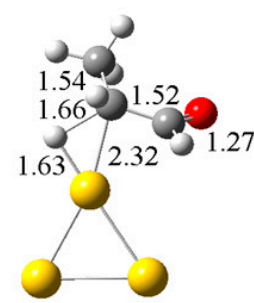

$3 \mathrm{TS}_{12}$

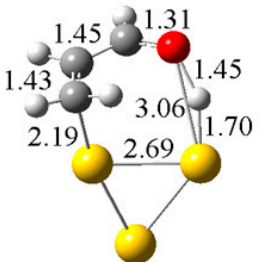

$3 \mathrm{TS}_{4}$

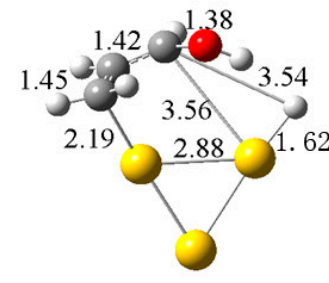

$3 \mathrm{IS}_{43}$

Figure 1. Adsorption geometries of acrolein hydrogenation on the Aus calculated at PW91/cep-121G level.

The next step of hydrogenation of the $\mathrm{C}=\mathrm{C}$ bond along route 12 is addition of $\mathrm{H}$ atom at $\mathrm{C} 2$. The co-adsorption of $\mathrm{H}$ atom and 3110 on the $\mathrm{Au}_{3}$ is shown in Figure 1. Like 3IS1, the $\mathrm{H}$ atom and the $\mathrm{C} 2$ atom also share the gold atom in 3IS12. In this co-adsorption structure, 3110 practically binds to Aus via C2-Au interaction. The C2-Au distance, $2.18 \AA$, is significantly shorter than $2.34 \AA$ in $3 S_{1}$. In the $3 \mathrm{TS}_{12}$, the $\mathrm{H}$ atom, $\mathrm{C} 2$ and the $\mathrm{Au}$ form a triangle structure. In the transition state $3 \mathrm{TS}_{12}$, the $\mathrm{H}-\mathrm{Au}$ bond length is $1.63 \AA$ and the $\mathrm{C} 2-\mathrm{H}$ bond distance decreases from $2.59 \AA$ to $1.66 \AA$. However, C1-C2, $\mathrm{C} 2-\mathrm{C} 3$ and $\mathrm{C}=\mathrm{O}$ bond lengths are almost unchanged. This shows that the influence of $\mathrm{H}$ attacking at 
C2 is relatively local. Product 3210 is saturated aldehyde and interacts with Aus via C2-Au (2.69 $⿱$ ) and C3-Au (2.59 A) interaction. Note the corresponding C1-C2 bond length and C2-C3 bond length are equal and is close to the $\mathrm{C}-\mathrm{C}$ bond length of ethane $(1.55 \AA)$ at the same level. This is understandable because $\mathrm{C} 1$ and $\mathrm{C} 2$ are "saturated". Kinetically, the energy barrier of 12 pathway is $0.35 \mathrm{eV}$, which shows that $\mathrm{C}=\mathrm{C}$ hydrogenation on $\mathrm{Au}$ is is likely (Table 1 ).

\subsubsection{Hydrogenation of the $\mathrm{C}=\mathrm{C}$ bond}

3IS4 is the initial state used for the first step of $\mathrm{C}=\mathrm{O}$ hydrogenation. To attack the $\mathrm{O}$ atom of $3 \mathrm{IS}_{4}$, the $\mathrm{H}$ atom first rotates which weakens the $\mathrm{O}-\mathrm{Au}$ bonding in the di- $\sigma-(\mathrm{C}, \mathrm{O})$-cis-AC mode[21]. In the $3 \mathrm{TS}_{4}$, the $\mathrm{H}$ atom is between the $\mathrm{O}$ atom and the $\mathrm{Au}$ with the $\mathrm{O}-\mathrm{H}$ and $\mathrm{H}-\mathrm{Au}$ bond lengths of 1.45 and $1.70 \AA$ respectively (Figure 1). The variation of $\mathrm{C} 1-\mathrm{C} 2, \mathrm{C} 2-\mathrm{C} 3, \mathrm{C} 3-\mathrm{O}$ and $\mathrm{C} 1-\mathrm{Au}$ is within $0.02 \AA$. Moreover, the Au-Au bond varies from $2.68 \AA$ to $2.69 \AA$, indicating a slightly stabilizing deformation of $\mathrm{Au}$. In addition, O-Au bond is decrease from $5.95 \AA$ in $3 \mathrm{IS}_{4}$ to $3.06 \AA$ in $3 \mathrm{TS}_{4}$, which shows that the $\mathrm{O}-\mathrm{Au}$ bond is also broken and the $\mathrm{O}$ atom does not interact with $\mathrm{Au}_{3}$ directly.

As in the $\mathrm{C}=\mathrm{C}$ hydrogenation, an intermediate product, $3 \mathrm{IM}_{4 \mathrm{~A}}$, is also formed firstly (Figure 1). In this case, the O-Au bond length is $2.46 \AA$, indicating that $\mathrm{O}-\mathrm{Au}$ bond is formed. The $\mathrm{H}-\mathrm{Au}$ bond is broken. $3 \mathrm{IM}_{4 \mathrm{~A}}$ is also not stable enough to be the final product because the saturated $\mathrm{O}$ atom produces an unpaired electron on C3, which makes C3 possess strong bonding ability. Transformation of $3 \mathrm{IM}_{4 \mathrm{~A}}$ into $3 \mathrm{IM}_{4 \mathrm{~B}}$ releases the heat of $0.32 \mathrm{eV}$.

Based on the $3 \mathrm{IM}_{4 \mathrm{~B}}$, we studied the second step of $\mathrm{C}=\mathrm{O}$ hydrogenation. $3 \mathrm{IS}_{43}$ shown in Figure 1 illustrates the initial structure (co-adsorptions structure) of $\mathrm{H}$ with 2111, the product of the first hydrogenation. The H-Au bond length is $1.62 \AA$. The C2-Au distance is elongated from $2.84 \AA$ of 3IM4B to $3.56 \AA$. In the $3 \mathrm{TS}_{43}$ the $\mathrm{H}$ atom links $\mathrm{C} 3$ and the $\mathrm{Au}$ with $\mathrm{H}-\mathrm{Au}$ and $\mathrm{H}-\mathrm{C} 3$ being 1.68 and $1.76 \AA$ respectively. As shown in Figure 1, the C3-O bond is elongated by $0.03 \AA$ due to $\mathrm{H}$ addition. The hydrogenation product $3 \mathrm{FS}_{43}$ is 2121 . Because the $\mathrm{C}=\mathrm{O}$ bond is hydrogenated, the $\mathrm{C} 2-\mathrm{C} 3$ bond length $(1.53 \AA)$ and $\mathrm{C} 3-\mathrm{O}$ bond length $(1.47 \AA)$ in $3 \mathrm{FS}_{43}$ are close to the $\mathrm{C}-\mathrm{C}$ single bond length in ethane (1.55 $\AA$ ) and C-O bond length in methanol. C1-C2 bond length is $0.07 \AA$ longer than $\mathrm{C}=\mathrm{C}$ double bond length (1.36 $\AA$ ) of the isolated acrolein. As shown in Figure 1, 2121 interacts with gold atom via $\pi$ - $\mathrm{C}=\mathrm{C}$ mode. The $\mathrm{C}=\mathrm{O}$ hydrogenation reaction on $\mathrm{Au} 3$ is an exothermic reaction with a reaction heat of $0.38 \mathrm{eV}$, which implies that $\mathrm{C}=\mathrm{O}$ hydrogenation on $\mathrm{Au}_{3}$ is favorable thermodynamically. However, the energy barrier of 43 pathway $(0.94 \mathrm{eV})$ is higher than that of 12 pathway $(0.35 \mathrm{eV})$, which indicates that on $\mathrm{Au}_{3} \mathrm{C}=\mathrm{C}$ hydrogenation is more favorable than $\mathrm{C}=\mathrm{O}$ hydrogenation.

\subsection{Acrolein hydrogenation on $A u_{5}$}

The most stable coadsorption structures of 2110 and $\mathrm{H}$ atom on $\mathrm{Au} 5$ were chosen as initial states (5IS 1 ) for $\mathrm{C}=\mathrm{C}$ and $\mathrm{C}=\mathrm{O}$ hydrogenation (Figure 2 ). In the $5 \mathrm{IS}_{1}$, acrolein interacts directly with $\mathrm{Au} 5$ via C-Au bond ( $2.21 \AA)$ and O-Au bond $(2.17 \AA)$. The $\mathrm{H}$ atom locates at the middle of Au-Au bond that can directly interact with 2110 and the corresponding $\mathrm{C} 1-\mathrm{H}$ and $\mathrm{O}-\mathrm{H}$ bond length is $2.55 \AA$ and 2.50 $\AA$ as shown in Figure 2. 


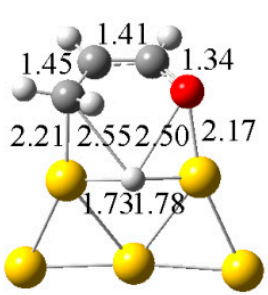

5IS

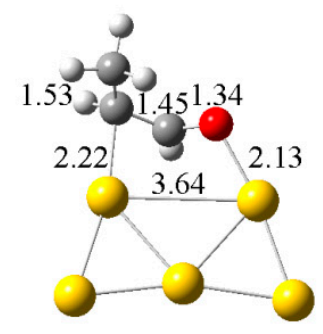

$5 \mathrm{IM}_{1 \mathrm{~B}}$
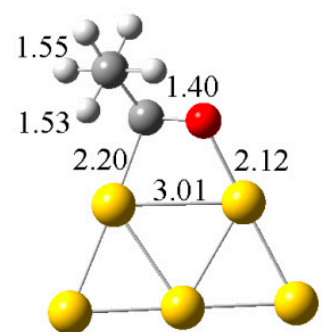

$5 \mathrm{FS}_{12}$

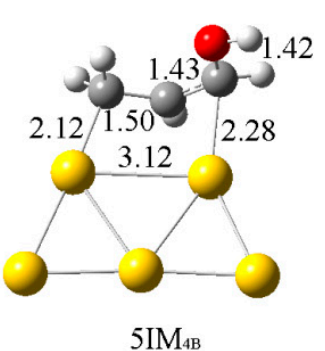

$5 \mathrm{IM}_{4 \mathrm{~B}}$

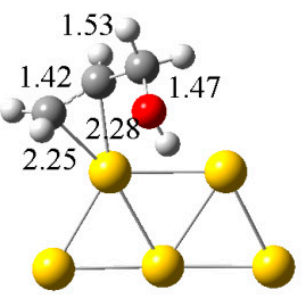

$5 \mathrm{FS}_{43}$

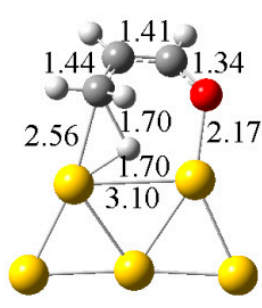

$5 \mathrm{TS}_{1}$

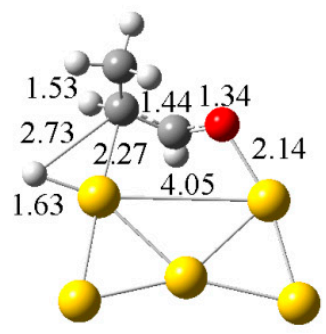

$5 \mathrm{IS}_{12}$

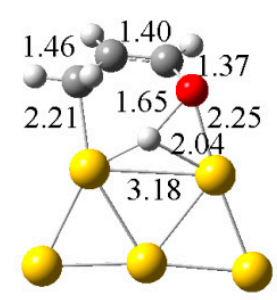

$5 \mathrm{TS}_{4}$

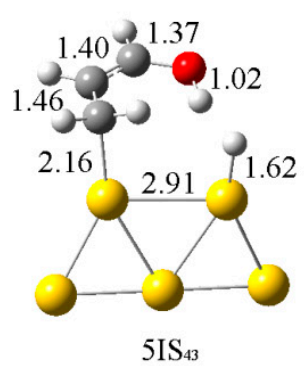

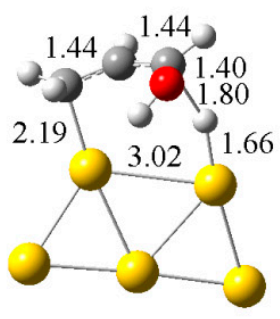

$5 \mathrm{TS}_{43}$
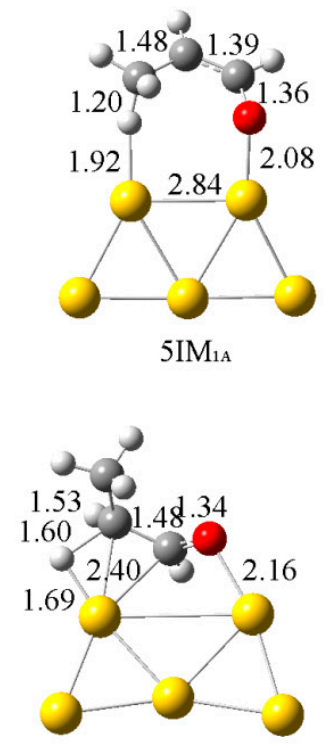

$5 \mathrm{TS}_{12}$

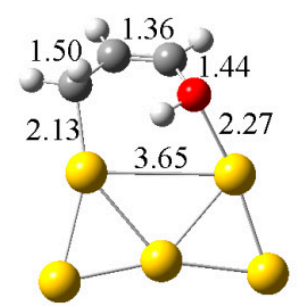

$5 \mathrm{IM}_{4 \mathrm{~A}}$ 
from $2.21 \AA$ to $2.56 \AA$ in the 5TS1. The C1-C2, C2-C3, C3-O and O-Au vary slightly (within $0.01 \AA$ ), indicating that the influence of $\mathrm{H}$ attacking at $\mathrm{C} 1$ atom is relatively local in the first step of $\mathrm{C}=\mathrm{C}$ bond hydrogenation. In the intermediate of $5 \mathrm{IM}_{1 \mathrm{~A}}(3110)$, the $\mathrm{Au}-\mathrm{H}$ bond and the $\mathrm{C} 1-\mathrm{H}$ bonds are $1.92 \AA$ and $1.20 \AA$ respectively. The $\mathrm{C} 1$ atom cannot interact directly with Au5. Hydrogenation of $\mathrm{C} 1$ produces a radical centered on $\mathrm{C} 2$ atom. However, in $5 \mathrm{IM}_{1 \mathrm{~A}} \mathrm{C} 2$ does no interact with Au5 directly. Thus, 5IM1A is not stable and can convert into more stable 5ІМ1в. Our calculated result indicates that this conversion is exothermic by $0.76 \mathrm{eV}$. In $5 \mathrm{IM}_{1 \mathrm{~B}}, 3110$ interacts with Aus by both $\mathrm{C} 2-\mathrm{Au}(2.22 \AA)$ and O-Au bond (2.13 $\AA$ ). Second hydrogenation starts from $5 \mathrm{IS}_{12}$. Attacking of the $\mathrm{H}$ to $\mathrm{C} 2$ site results in the transition state $5 \mathrm{TS}_{12}$. In the $5 \mathrm{TS}_{12}$, the $\mathrm{H}-\mathrm{C} 2$ distance is $1.60 \AA$ and the $\mathrm{C} 2$ - $\mathrm{Au}$ bond distance is $2.40 \AA$. In $5 \mathrm{FS}_{12}$, the $\mathrm{C}=\mathrm{O}$ bond of 3210 directly interacts with $\mathrm{Au} 5$ in the di- $\sigma-\mathrm{C}=\mathrm{O}$ mode with the C3-Au bond length of $2.20 \AA$ and O-Au bond length of $2.12 \AA$. Because $\mathrm{C}=\mathrm{C}$ bond is saturated by $\mathrm{H}$ atoms, C1-C2 bond length in $5 \mathrm{FS}_{12}$ is $1.55 \AA$ and is equal to that in ethane, accompanied by an elongation of $\mathrm{C} 2-\mathrm{C} 3$ bond from $1.44 \AA$ in $5 \mathrm{IS}_{12}$ to1.53 $\AA$. The rate-determining step of $\mathrm{C}=\mathrm{C}$ hydrogenation reaction on $\mathrm{Au}_{5}$ is exothermic by $0.62 \mathrm{eV}$ with a low energy barrier of $0.54 \mathrm{eV}$.

\subsubsection{Hydrogenation of the $\mathrm{C}=\mathrm{O}$ bond}

The first step of $\mathrm{C}=\mathrm{O}$ hydrogenation also begins with $5 \mathrm{IS}_{1}$. This reaction (from $5 \mathrm{TS}_{4}$ to $5 \mathrm{IM}_{4 \mathrm{~A}}$ ) starts with the $\mathrm{H}$ atom approaching toward to the O-Au bond, which increases the O-Au distance from $2.17 \AA$ in $5 \mathrm{IS}_{1}$ to $2.25 \AA$ in $5 \mathrm{TS}_{4}$, indicating that the O-Au bond is weakened. Similar to the transition state $3 \mathrm{TS}_{4}$, the $\mathrm{H}$-Au bond length is $2.04 \AA$ and the $\mathrm{O}-\mathrm{H}$ distance is $1.65 \AA$ in the $5 \mathrm{TS}_{4}$. The C-O distance increases from $1.34 \AA$ in $5 \mathrm{IS}_{1}$ to $1.37 \AA$ in $5 \mathrm{TS}_{4}$. However, C1-Au, C1-C2 and C2-C3 bond lengths are almost unchanged (within $0.01 \AA$ ). This shows that the influence of $\mathrm{H}$ attacking at $\mathrm{O}$ is relatively local.

In the final state, $5 \mathrm{IM}_{4 \mathrm{~A}}$, the $\mathrm{O}-\mathrm{Au}$ bond is $2.27 \AA$, indicating that the O-Au interaction is still significant. Unlikely $5 \mathrm{IM}_{1 \mathrm{~A}}, 5 \mathrm{IM}_{4 \mathrm{~A}}$ can interact directly with $\mathrm{Au}_{5}$ via O-Au bond. Because hydrogenation at the $\mathrm{O}$ atom, the $\mathrm{C} 3$ atom of $\mathrm{C}=\mathrm{O}$ bond becomes a radical. Thus, a stable adsorption structure should involve $\mathrm{C} 3$. Our computation indicates that $5 \mathrm{IM}_{4 \mathrm{~B}}$ is $0.39 \mathrm{eV}$ more stable than $5 \mathrm{IM}_{4 \mathrm{~A}}$. In $5 \mathrm{IM}_{4 \mathrm{~B}}$, the $\mathrm{C} 3-\mathrm{Au}$ bond distance is $2.28 \AA$ in the $5 \mathrm{IM} 4 \mathrm{~B}$, and the product 2111 is stabilized by both $\mathrm{C} 1-\mathrm{Au}$ and $\mathrm{C} 3-\mathrm{Au}$ bonding. The second step of $\mathrm{C}=\mathrm{O}$ hydrogenation begins with coadsorption state (5IS 43$)$ of $\mathrm{H}$ atom and 2111. In the initial state (5IS43) the $\mathrm{H}$ atom sits at the top site of a Au atom with $\mathrm{H}$-Au distance of $1.62 \AA$. Due to the $\mathrm{H}$-Au bond, the $\mathrm{C} 3-\mathrm{Au}$ bond no longer exists. In the TS structure $5 \mathrm{TS}_{43}$, the $\mathrm{H}-\mathrm{C} 3$ is $1.80 \AA$ and the $\mathrm{H}$-Au bond is elongated from 1.62 to $1.66 \AA$, showing that the $\mathrm{H}-\mathrm{Au}$ interaction is only slightly weakened. The final product is $2121\left(5 \mathrm{FS}_{43}\right)$. It adsorbs on $\mathrm{Au} 5 \mathrm{via}$ the $\pi$ - $\mathrm{C}=\mathrm{C}$ - mode. The rate-determining step of the $\mathrm{C}=\mathrm{O}$ hydrogenation reaction on $\mathrm{Au}_{5}$ is an exothermic reaction with a reaction heat of $-0.25 \mathrm{eV}$. The energy barrier is $0.45 \mathrm{eV}$. Compared to the barrier of $\mathrm{C}=\mathrm{C}$ hydrogenation on $\mathrm{Au} 5$, we can conclude that on $\mathrm{Au} 5 \mathrm{C}=\mathrm{O}$ hydrogenation is more favorable than $\mathrm{C}=\mathrm{C}$ hydrogenation kinetically.

\subsection{Competition of the $\mathrm{C}=\mathrm{C}$ and $\mathrm{C}=\mathrm{O}$ hydrogenation}

Figure 3 and Figure 4 summaries the PES for the $\mathrm{C}=\mathrm{C}$ and $\mathrm{C}=\mathrm{O}$ hydrogenation on $\mathrm{Au} 3$ and Aus. The calculated barrier for the first and second steps of the $\mathrm{C}=\mathrm{C}$ bond hydrogenation of acrolein (R12 pathway) are $0.29\left(3 \mathrm{TS}_{1}\right)$ and $0.35\left(3 \mathrm{TS}_{12}\right) \mathrm{eV}$. These two barriers are close to each others, though the latter is slightly higher than the former. Both reactions are essentially neutral with the endothermicity of less than $0.05 \mathrm{eV}$. Note the co-adsorbed intermediate $3 \mathrm{IM}_{1 в}$ with $\mathrm{H}(0.56 \mathrm{eV})$ is 
more stable than the precursor 3IS12. Therefore, thermodynamically the second step is more difficult and thus, control the production of 3210 , the product of the $\mathrm{C}=\mathrm{C}$ bond hydrogenation.

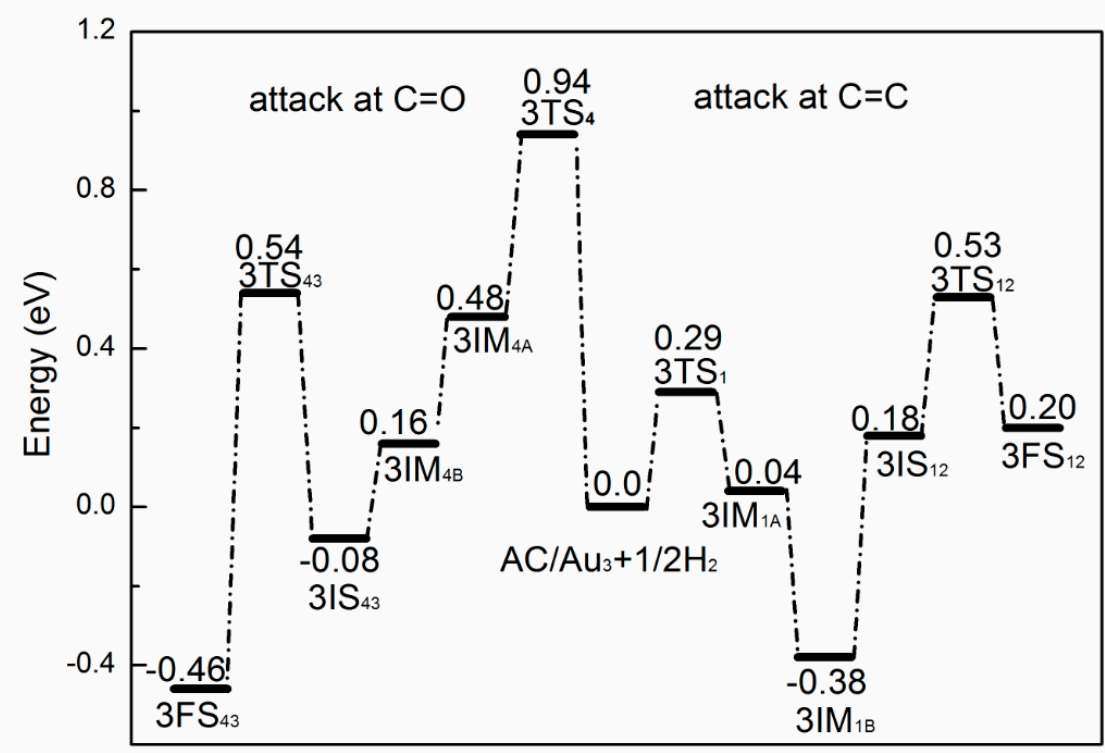

Figure 3. Pathways of acrolein(AC) hydrogenation on Aus. The energies of the IS plus half of the energy of an isolated $\mathrm{H}_{2}$ molecule is taken as the zero energy reference point $\left(\mathrm{AC} / \mathrm{Au}_{3}+1 / 2 \mathrm{H}_{2}\right)$. All the energies of IMs and TSs for the first step are referred to the energies of the adsorbed structure together with half of the energy of the free $\mathrm{H}_{2}$ molecule.

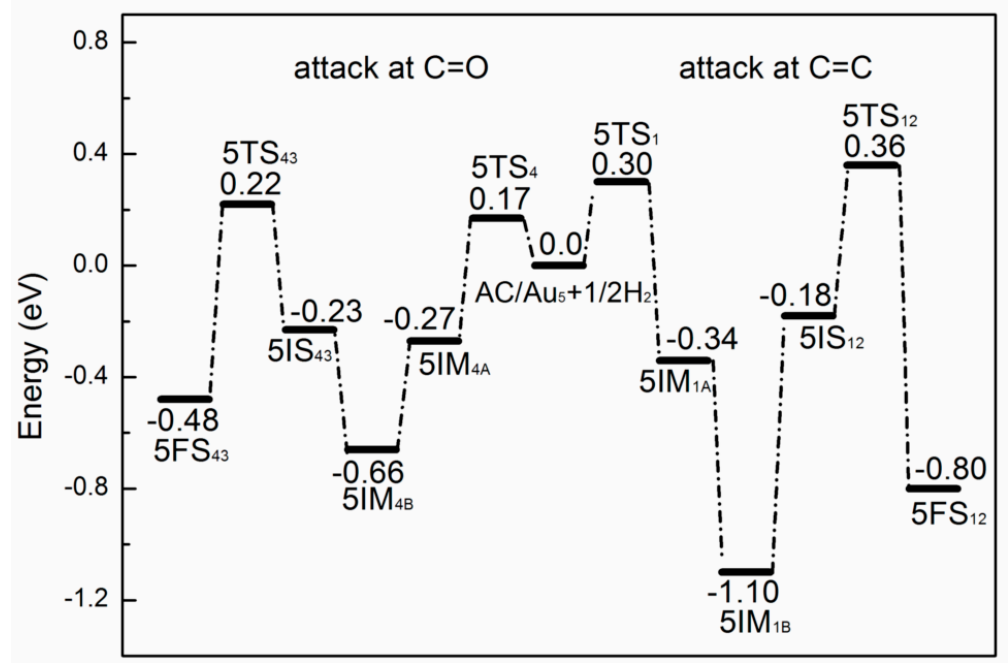

Figure 4. Pathways of acrolein(AC) hydrogenation on Aus. The energies of the IS plus half of the energy of an isolated $\mathrm{H}_{2}$ molecule is taken as the zero energy reference point $\left(\mathrm{AC} / \mathrm{Au}_{5}+1 / 2 \mathrm{H}_{2}\right)$

On the other hand, the barrier for the $\mathrm{C}=\mathrm{O}$ hydrogenation are $0.94\left(3 \mathrm{TS}_{4}\right)$ and $0.62\left(3 \mathrm{TS}_{43}\right) \mathrm{eV}$, which are also similar to the step hydrogenation of $\mathrm{C}=\mathrm{C}$ bond on $\mathrm{Au}_{3}$ (Figure 3). The first step to $3 \mathrm{IM} 4 \mathrm{~A}$ is endothermic whereas conversion to the most stable structure releases heat of $0.48 \mathrm{eV}$. The second hydrogenation step lowers the energy of the system by $0.46 \mathrm{eV}$.

Compared with the energy barrier of 12 , we found that $C=C$ hydrogenation with the highest energy barrier of $0.35 \mathrm{eV}$, is more favorable than $\mathrm{C}=\mathrm{O}$ hydrogenation with the highest barrier of 0.94 $\mathrm{eV}$. This result is in agreement with the experimental observation that the yield of $\mathrm{C}=\mathrm{C}$ reduction is higher than that of the $\mathrm{C}=\mathrm{O}$ hydrogenation. 
The stepwise hydrogenation barriers of $\mathrm{C}=\mathrm{C}$ bond on $\mathrm{Au} 5$ are $0.30\left(5 \mathrm{TS}_{1}\right)$ and $0.54 \mathrm{eV}$ (Figure 4) respectively. The most stable intermediate $5 \mathrm{IM}_{1 \mathrm{~B}}$ is almost $1 \mathrm{eV}$ lower in energy than the precursor $5 \mathrm{IS}_{12}$, indicating that formation of $\mathrm{IIS}_{12}$ is thermodynamically less likely. Thus, the second step is the rate-limiting step. Both reactions are exothermic, $>0.3 \mathrm{eV}$ (Figure 4). For the $\mathrm{C}=\mathrm{O}$ hydrogenation (43 pathway), the corresponding energy barriers are 0.17 and $0.45 \mathrm{eV}$, which also shows that the second step is rate-determining step. The calculated results show that $\mathrm{C}=\mathrm{O}$ hydrogenation barriers is slightly lower than the corresponding values for the $C=C$ hydrogenation, indicating that $C=O$ reduction is preferred on Aus.

\subsection{Comparison of acrolein hydrogenation on $\mathrm{Au}_{3}$ and $\mathrm{Au} 5$}

Above we discussed the kinetics of $\mathrm{C}=\mathrm{C}$ and $\mathrm{C}=\mathrm{O}$ hydrogenation on $\mathrm{Au}_{3}$ and $\mathrm{Au} 5$ clusters respectively. Now we compare the $\mathrm{C}=\mathrm{C}$ hydrogenation on $\mathrm{Au}_{3}$ and $\mathrm{Au}$. The energy barrier of 3TS $\left(0.29 \mathrm{eV}\right.$ on $\left.\mathrm{Au}_{3}\right)$ for the first hydrogenation step is almost equal to that of $5 \mathrm{TS}_{1}(0.30 \mathrm{eV}$ on $\mathrm{Au} 5)$. However, the energy barrier of $5 \mathrm{TS}_{12}\left(0.54 \mathrm{eV}\right.$ on Aus) is $0.19 \mathrm{eV}$ higher than that of $3 \mathrm{TS}_{12}(0.35 \mathrm{eV}$ on $\left.\mathrm{Au}_{3}\right)$, indicating that the energy barrier of $\mathrm{C}=\mathrm{C}$ hydrogenation increases from $\mathrm{Au}_{3}$ to $\mathrm{Au}$.

For $\mathrm{C}=\mathrm{O}$ hydrogenation on $\mathrm{Au}_{3}$ and $\mathrm{Au}$, the calculated energy barrier of $3 \mathrm{TS}_{4}(0.94 \mathrm{eV})$ in the first step is $0.77 \mathrm{eV}$ higher than that of $5 \mathrm{TS}_{4}(0.17 \mathrm{eV})$. Moreover, in the second step, the energy barrier of $3 \mathrm{TS}_{43}(0.62 \mathrm{eV})$ is $0.17 \mathrm{eV}$ higher than that of $5 \mathrm{TS}_{43}(0.45 \mathrm{eV})$. These results indicate that the energy barrier of $\mathrm{C}=\mathrm{O}$ hydrogenation decreases from $\mathrm{Au} 3$ to $\mathrm{Au} 5$.

To recap, $\mathrm{C}=\mathrm{C}$ hydrogenation is favored on $\mathrm{Au}_{3}$ (the energy barrier of the rate-limiting step: $0.35 \mathrm{eV}$ for $\mathrm{C}=\mathrm{C}$ vs $0.94 \mathrm{eV}$ for $\mathrm{C}=\mathrm{O})$ while the $\mathrm{C}=\mathrm{O}$ hydrogenation is preferred on $\mathrm{Au} 5(0.45 \mathrm{eV}$ for $\mathrm{C}=\mathrm{O}$ vs. $0.54 \mathrm{eV}$ for $\mathrm{C}=\mathrm{C}$ ). These facts indicate that the selectivity of acrolein hydrogenation has close relationship with cluster size, which is consistent with the experiments observation that the activity and selectivity to the desired unsaturated alcohol depends on particle size and increases with increasing particle size[17,23-24].

In addition, we also compare the comparison of acrolein hydrogenation on $\mathrm{Au}(110)$ and $\mathrm{Au} 20$ clusters.

\section{Models and computational details}

Calculations were performed using generalized gradient functional PW91[25, 26] implemented in Gaussian 03 program package.[27] We used the effective core potential (ECP) basis set, cep-121G (6D, 10F) for Au, C and O,[28, 29] and a triple zeta basis set for H.[30] Frequency calculations were performed to characterize all the optimized structures to be local minima or transition states on the potential energy surfaces. The intrinsic reaction coordinate calculations were further carried out to ensure that the obtained transition states connect the right reactants and products.

\section{Conclusion}

The selective hydrogenation acrolein on the small gold cluster $\mathrm{Au}_{3}$ and $\mathrm{Au}_{5}$ is investigated using density functional theory PW91 functional. The mechanism is explored along two pathways: hydrogenation of $\mathrm{C}=\mathrm{C}$ bond and $\mathrm{C}=\mathrm{O}$ group. We show that on $\mathrm{Au}_{3} \mathrm{C}=\mathrm{C}$ hydrogenation is more favorable than that of $\mathrm{C}=\mathrm{O}$ bond with the corresponding barrier of rate-determining step of $0.35 \mathrm{eV}$ vs $0.94 \mathrm{eV}$. On the other hand, on $\mathrm{Au}_{5}, \mathrm{C}=\mathrm{O}$ reduction is favored than hydrogenation of $\mathrm{C}=\mathrm{C}$ bond. The corresponding barriers of the rate-determining steps are 0.45 and $0.54 \mathrm{eV}$, respectively. 
Comparison of the present results on $\mathrm{Au}_{3}$ and $\mathrm{Au}_{5}$ indicated that the large particles favor the $\mathrm{C}=\mathrm{O}$ hydrogenation, which is consistent with the experiments observation.

Supplementary Materials: The following are available online at www.mdpi.com/link, Figure A1: Potential energy surfaces of first hydrogenation step of acrolein on Au3, Figure A2: Potential energy surfaces of second hydrogenation step of acrolein on Au3, Figure A3: Potential energy surfaces of first hydrogenation step of acrolein on Au5, Figure A4: Potential energy surfaces of second hydrogenation step of acrolein on Aus.

Acknowledgments: Financial supports from the Fundamental Research Funds for the Central Universities (No. 2013QNA14). We are grateful to the High Performance Computing Center of China University of Mining and Technology for the award of CPU hours to accomplish this work. We would like to thank Prof. Zhaoxu Chen for many stimulating discussions.

Author Contributions: Guo-Jun Kang performed the calculation work and wrote the paper work. Shuai He collected and analyzed the calculated results; Xue-Feng Ren revised the paper.

Conflicts of Interest: The authors declare no conflict of interest.

\section{References}

[1] Gallezot, P.; Richard DSelective Hydrogenation of $\alpha, \beta$-Unsaturated Aldehydes, Cat. Rev. Sci. Eng. 1998, 40, 81-126.

[2] Marinelli, T.B.L.W; Nabuurs, S.; Ponec, V. Activity and Selectivity in the Reactions of Substituted $\alpha, \beta$-Unsaturated Aldehydes J. Catal. 1995, 151, 431-438.

[3] Claus, P. Selective hydrogenation of $\alpha, \beta$-unsaturated aldehydes and other $\mathrm{C}=\mathrm{O}$ and $\mathrm{C}=\mathrm{C}$ bonds containing compounds, Top. Catal. 1998, 5, 51-62.

[4] Brandt, K.; Chiu, M.E.; Watson, D.J.; Tikhov, M.S.; Lambert RMChemoselective Catalytic Hydrogenation of Acrolein on Ag(111): Effect of Molecular Orientation on Reaction Selectivity, J. Am. Chem. Soc. 2009, 131, 17286-17290.

[5] Lim, K.H.; Mohammad, A.B.; Yudanov, I.V.; Neyman, K.M.; Bron, M.; Claus, P.; Rösch, N. Mechanism of Selective Hydrogenation of $\alpha, \beta$-Unsaturated Aldehydes on Silver Catalysts: A Density Functional Study, J. Phys. Chem. C 2009, 113, 13231-13240.

[6] Lim, K.H.; Chen, Z.X.; Neyman, K.M.; Rosc,h N.; Adsorption of acrolein on single-crystal surfaces of silver: Density functional studies, Chem. Phys. Lett. 2006, 420, 60-64.

[7] Ferullo, R.M.; Marta Branda, M.; Illas, F. Structure and stability of acrolein and allyl alcohol networks on $\operatorname{Ag}(111)$ from density functional theory based calculations with dispersion corrections, Surf. Sci. 2013, 617, 175-182.

[8] Kliewer, C.J.; Bieri, M.; Somorjai, G.A. Hydrogenation of the $\alpha, \beta$-Unsaturated Aldehydes Acrolein, Crotonaldehyde, and Prenal over Pt Single Crystals: A Kinetic and Sum-Frequency Generation Vibrational Spectroscopy Study, J. Am. Chem. Soc. 2009, 131, 9958-9966.

[9] Loffreda, D.; Delbecq, F.; Vigne, F.; Sautet, P. Chemo-Regioselectivity in Heterogeneous Catalysis: Competitive Routes for CO and CC Hydrogenations from a Theoretical Approach, J. Am. Chem. Soc. 2006, 128, 1316-1323.

[10] Marinelli, T.B.L.W.; Ponec, V. A Study on the Selectivity in Acrolein Hydrogenation on Platinum Catalysts: A Model for Hydrogenation of $\alpha, \beta$-Unsaturated Aldehydes J. Catal. 1995, 156:51-59.

[11] Pirillo, S.; López-Corral, I.; Germán, E.; Density Functional Study of Acrolein Adsorption on Pt(111), Juan, A. 2014, 99, 259- 264.

[12] Murillo, L. E.; Menning, C.A.; Chen, J.G. Trend in the Cdouble bond; length as m-dashC and Cdouble bond; length as m-dashO bond hydrogenation of acrolein on $\mathrm{Pt}-\mathrm{M}(\mathrm{M}=\mathrm{Ni}, \mathrm{Co}, \mathrm{Cu})$ bimetallic surfaces, J. Catal. 2009, 268, 335-342. 
[13] Luo, Q.; Wang, T.; Beller, M.; Jiao, H. Acrolein Hydrogenation on Ni(111) J. Phys. Chem. C 2013, 117, 12715-12724.

[14] Claus, P. Heterogeneously catalysed hydrogenation using gold catalysts, Appl. Catal. A Gen. 2005, 291,222-229.

[15] Claus, P.; Hofmeister, H.; Mohr, C. Identification of active sites and influence of real structure of gold catalysts in the selective hydrogenation of acrolein to allyl alcohol Gold. Bull. 2004, 37, 181-186.

[16] Milone, C.; Crisafulli, C.; Ingoglia, R.; Schipilliti, L.; Galvagno, S. A comparative study on the selective hydrogenation of $\alpha, \beta$ unsaturated aldehyde and ketone to unsaturated alcohols on Au supported catalysts, Catal. Today, 2007, 122, 341-351.

[17] Mohr, C.; Hofmeister, H.; Radnik, J.; Claus, P. Identification of Active Sites in Gold-Catalyzed Hydrogenation of Acrolein, J. Am. Chem. Soc. 2003, 125, 1905-1911.

[18] He, X.; Chen, Z.X.; Kang, G.J. Theoretical Study of the Role of Indium on the Selectivity of Acrolein Hydrogenation to Propenol on Gold Surfaces, J Phys. Chem. C 2009, 113, 12325-12330.

[19] Horiuti, J.; Polanyi, M. Exchange reactions of hydrogen on metallic catalysts Trans. Faraday. Soc. 1934, 30, 1164-1172.

[20] Kang, G.J.; Chen, Z.X.; Li, Z.; He, X. A theoretical study of the effects of the charge state and size of gold clusters on the adsorption and dissociation of H-2 J. Chem. Phys. 2009, 130, 034701-034706.

[21] Kang, G.-J.; Chen, Z.-X.; Li, Z. Acrolein Adsorption on Gold Clusters, A Theoretical Study of Conjugation Effect on $C=C$ and C=O Interaction with Au Clusters, Catal. Lett. 2011, 141, 996-1003.

[22] Kang, G.-J.; Ma, J.; Chen, Z.-X. Theoretical Studies of Species Related to Acrolein Hydrogenation, Catal. Lett. 2012, 142, 287-293.

[23] Claus, P.; Brückner, A.; Mohr, C.; Hofmeister, H. J. Am. Chem. Soc. 2000, 122, 11430-11439.

[24] Mohr, C.; Hofmeister, H.; Claus, P. The influence of real structure of gold catalysts in the partial hydrogenation of acrolein J. Catal. 2003, 213, 86-94.

[25] Perdew, J.P; Chevary, J.A; Vosko, S.H; Jackson, K.A; Pederson, M.R; Singh, D.J.; Fiolhais, C. Atoms, molecules, solids, and surfaces: Applications of the generalized gradient approximation for exchange and correlation Phys. Rev. B 1992, 46, 6671-6687.

[26] Perdew, J.P; Chevary, J.A; Vosko, S.H; Jackson, K.A; Pederson, M.R; Singh, D.J.; Fiolhais, C. Erratum: Atoms, molecules, solids, and surfaces: Applications of the generalized gradient approximation for exchange and correlation, Phys. Rev. B 1993, 48, 4978(E).

[27] Frisch, M.J.; Trucks, G.W.; Schlegel, H.B.; Scuseria, G.E.; Robb, M.A. (2004) Gaussian 03, Revision D.01,Gaussian, Inc., Wallingford CT, 2004.

[28] Stevens. W.J.; Basch, H.; Krauss, M. Compact effective potentials and efficient shared-exponent basis sets for the first- and second-row atoms, J Chem. Phys., 1984, 81, 6026-6033.

[29] Stevens, W.J.; Krauss, M.; Basch, H.; Jasien, P. G. Relativistic compact effective potentials and efficient, shared-exponent basis sets for the third-, fourth-, and fifth-row atoms, Can. J. Chem. 1992, 70, 612-630.

[30] Krishnan, R.; Binkley, J.S.; Seeger, R.; Pople, J.A. Self-consistent molecular orbital methods. XX. A basis set for correlated wave functions, J. Chem. Phys. 1980, 72:650-654.

Sample Availability: Samples of the compounds are available from the authors.

(C) 2016 by the authors; licensee Preprints, Basel, Switzerland. This article is an open access article distributed under the terms and conditions of the Creative Commons by Attribution (CC-BY) license (http://creativecommons.org/licenses/by/4.0/). 